\title{
Erratum to: Satisfaction with Health Informatics System Characteristics and Their Effect on Openness to Frequent Use
}

\author{
Karoly Bozan and Pratim Datta
}

\author{
Erratum to: \\ Chapter 7 in: N. Wickramasinghe et al. (eds.), Contemporary Consumer Health \\ Informatics, Healthcare Delivery in the Information Age, \\ DOI 10.1007/978-3-319-25973-4_7
}

The publisher regrets to inform that the name of the co-author (Pratim Datta) of Chapter 7 was missing in ToC and in the Chapter opening page of the print and online versions of the book. His affiliation and bio have been updated in the original chapter and are mentioned below:

Pratim Datta Kent State University College of Business Administration, P.O. Box 5190, Terrace Drive, Kent, OH 44242, USA

Pratim Datta (Ph.D.) is a two-time Farris Family Research Innovation Fellow and an Associate Professor of IS and Supply Chains at Kent State University. Ranked among the top 40 researchers internationally, Datta has over 55 journal articles and conference proceedings with multiple best paper awards. Datta focuses on IS and supply chain use, performance and security as well as cross-functional corporate decision-making. He has won the Paul Pfeiffer Professional and Teaching Award. He has also received the Outstanding MBA Professor Award and he is the showcased professor for the Executive MBA Program.

The online version of the original chapter can be found under

DOI 10.1007/978-3-319-25973-4_7

K. Bozan $(\square)$

Office: Room 540, 921 South 8th Avenue, Pocatello, ID 83209, USA

e-mail: bozakaro@isu.edu

P. Datta

Kent State University College of Business Administration, P.O. Box 5190,

Terrace Drive, Kent, OH 44242, USA

e-mail:pdatta@kent.edu

(C) Springer International Publishing Switzerland 2016

E1

N. Wickramasinghe et al. (eds.), Contemporary Consumer Health Informatics,

Healthcare Delivery in the Information Age, DOI 10.1007/978-3-319-25973-4_26 